\title{
Correction to: Genetic diversity and population structure of Jamunapari goat in India using pedigree analysis
}

\author{
Ajoy Mandal ${ }^{1} \cdot$ Hasan Baneh $^{2} \cdot$ R. Roy ${ }^{3}$ - D. R. Notter ${ }^{4}$ \\ Published online: 28 April 2021 \\ (C) Springer Nature B.V. 2021
}

\section{Correction to: Tropical Animal Health and Production (2021) 53:218} https://doi.org/10.1007/s11250-021-02638-x

The originally published version of this article contains an error. The 3rd mathematical expression found in section Statistical methods on page 2 was missing the minus symbol. The correct expression is shown below.

$\Delta C_{j k}=1-\frac{(g j+g k)}{2} \sqrt{C_{j k}}$

The original article has been corrected.

Publisher's note Springer Nature remains neutral with regard to jurisdictional claims in published maps and institutional affiliations.

The online version of the original article can be found at https://oi.org/ $10.1007 / \mathrm{s} 11250-021-02638-\mathrm{x}$

Ajoy Mandal

ajoymandal@gmail.com; ajoymandal@rediffmail.com

1 Present address: Animal Breeding Section, ICAR-National Dairy Research Institute, Eastern Regional Station, Kalyani, West Bengal 741235, India

2 Present address: Digital Agriculture Laboratory (DAL), Skolkovo Institute of Science and Technology, 121205 Moscow, Russia

3 Present address: Shivpuri, Lalbahadur Shastri Nagar, Patna, Bihar 800023, India

4 Present address: Department of Animal and Poultry Sciences, Virginia Tech, Blacksburg, VA, USA 